\title{
APPLICATION OF DESIGN ANALYSIS TO SOLUTION GENERATION: HAND-ARM VIBRATIONS IN FOUNDATION PILE HEAD REMOVAL IN THE CONSTRUCTION INDUSTRY
}

\author{
Paul Swuste ${ }^{a, *}$, Dik van Drimmelen ${ }^{b}$, Alex Burdorf ${ }^{c}$ \\ ${ }^{a}$ Safety Science Group, Delft University of Technology. Kanaalweg 2B, 2628 EB Delft. \\ Netherlands \\ ${ }^{\mathrm{b}}$ Public Transport, Amsterdam, Netherlands \\ 'Department of Public Health, Erasmus Unieersity, Rotterdam, Netherlands
}

\begin{abstract}
Impact power tools are still widely used by many professions. Users of these tools are exposed to high levels of both vibration and shock. Reported health effects due to hand-arm vibration are 'hand-arm vibration syndrome' (HAVS) and bone and joint injuries and disorders. In the construction industry a case study was conducted on one specific activity: removing concrete from the head of foundation piles. Pile heads are removed to allow the reinforcement rods to be connected to the rest of the foundation. Factors determining the vibration exposure were measured and the type and size of other occupational hazards were assessed qualitatively. The results showed that there was excessive exposure to vibration from the widely used hand-operated pneumatic drill as well as high exposure to other occupational hazards. The age of the drill, the make, the working pressure and the presence of a buffer ring have measurable effects on the level of vibration. But these adjustments only have a limited effect on the total workload. Instead of an exposure-oriented solution the present workload requires source-oriented solutions, which are expected to be more effective. A systematic approach towards the generation of possible solutions was adopted following the individual steps of the 'problemsolving cycle', in combination with the design analysis technique. Design analysis is a method which can generate different types of solutions resulting in a reduction of the various hazards to an acceptable level. (C) 1997 Elsevier Science Ltd. All rights reserved.
\end{abstract}

\section{Introduction}

High-impact percussive pneumatic tools are used in many different workplaces and frequently generate unacceptable levels of acceleration, resulting in high levels of exposure to hand-arm vibration. Exposure of the hands and fingers to vibration can result in a complex combination of vascular and neuromuscular disorders. These include impeded blood circulation in the fingers, 'attacks' of blanching of one or more digits. This condition is called the 'hand-arm vibration syndrome' (HAVS) (Taylor, 1988).

\footnotetext{
Corresponding author.
} 
In the Netherlands a detailed estimation showed that 20000 workers experience exposure to hand-arm vibration of $10-40 \mathrm{~ms}^{-2}$, due to working with percussive pneumatic tools. The average exposure time of this group is estimated to be one hour per day. 10000 of these workers experience this acceleration level with an average exposure time of at least four hours a day (Musson et al., 1989). These high levels of vibration of hand-held machines are described elsewhere as well (Jacobsson et al., 1992).

A recent publication of the European Community defines an eight-hour action level of exposure to hand-arm vibration of $2.5 \mathrm{~ms}^{-2}$. Above this level adequate measures must be taken to reduce the emission and/or the exposure. Up till now no adequate and practical personal protective equipment is available, as stated in the EC publication (EG, 1994). The control of these high levels of exposure has been the subject of a number of publications (Hessels et al., 1988; van Drimmelen et al., 1989; Wasserman, 1989; Griffin, 1990; Andersson, 1990; Wasserman and Taylor, 1991). The control measures and solutions mentioned start with improved engineering, followed by better design of the vibrating hand-tools and their maintenance.

The levels of acceleration in the high-impact percussive pneumatic tools are functional. They are necessary to break, compress or mechanically deform material. Therefore preventive measures which reduce the vibration level in general also reduce the effectiveness of the pneumatic tool and consequently are only possible in a limited way. The Dutch Arbeidsomstandighedenwet (Working Environment Law) requires employers to provide for "as high a level of safety as possible" for the layout of the workplace, the choice of production and work methods taking into account "the gencrally known principles and rules of technology, and the state of the art of occupational health, ergonomics and labour or management science'". These general requirements can be translated into a number of decision steps which the employer must logically follow to arrive at the preventive measures to be taken for a specific workplace. These steps are laid down in the problem-solving cycle and serve as an organising principle for safety and health management (Hale, 1985; Hale et al., 1990, 1997).

In this article, hand-operated impact breaking of pile heads using a pneumatic drill is taken as an example by means of which the possible solutions and preventive measures resulting from the problem-solving cycle can be explored.

\subsection{Foundation-pile-head removal}

Laying bare the reinforcing rods of concrete pile heads is part of the construction process for houses and buildings in the Netherlands. In the absence of load-bearing soil at the surface of the western part of the country, armoured concrete piles have to be driven onto pleistocene layers $10 \mathrm{~m}$ to $30 \mathrm{~m}$ underground. To connect the tops of these piles to the rest of the concrete foundations, the reinforcing rods of the head have to be laid bare.

In practice the pile is either prefabricated and driven into the soil by a pile-driving rig or is fabricated by 'on-side pouring'. By 'on-site pouring' a hole is drilled, the reinforcing rods are positioned into the hole and the concrete is poured round them. In both cases the reinforcing rods are then laid bare by removing the concrete at the head of a pile. The process normally used is a mechanical one: hand-operated with breaking impact tools. The impact is caused by repeated accumulation and release of pneumatic energy in a mass and the operation is controlled by hand. The pneumatic drill has a weight between $13-15 \mathrm{~kg}$ and the chisel registers 800 impacts per minute. Pneumatic drills have a long life and consequently old-fashioned designs are still widely used. During concrete removal, the worker holds the 
pneumatic drill with one hand and presses it against the pile. The other hand grips the chisel cowl holder and supports the drill and keeps it in position. An operator can remove the concrete from a pile head in 3 to 15 minutes, depending on the size, the position and the quality of reinforcing rods and concrete. This includes the removal of pieces by hand. $80 \%$ of that time is spent breaking concrete. The average exposure time is four hours a day or more. There is no official training course on how to correctly operate a pneumatic drill. Instructions are passed on by the operator spending around a year with a more experienced pile-head remover.

\section{Materials and methods}

\subsection{Problem-solving cycle}

The detection and correction of deviations, either occupational accidents or diseases or other undesirable outcomes of industrial activity, can be seen as a problem-solving activity. This activity can take place at different levels from the direct execution of actions to control danger, through the establishment of a safety and health system, up to the monitoring and evaluation thereof. The problem-solving cycle has been introduced as an organising principle for safety and health-management activities. The steps to be distinguished are shown in Fig. 1, and emphasise the feedback loop driving continuous assessment and learning. This model defines tasks to be accomplished in relation to any safety and health problem (Hale and Glendon, 1987).

Problem solving cycle

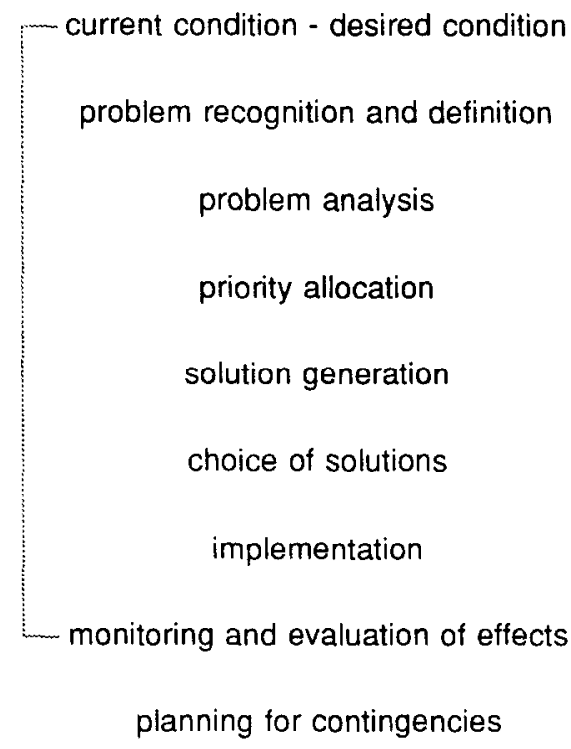

Fig. 1. Problem solving cycle. 
In the first two steps, the comparison of the actual condition with the desired one leads to a problem recognition and definition. The criteria for 'danger' must he defined, for example the desired condition may be a reduced exposure to an occupational danger or compliance with the law, regulations or in-house standards.

The problem analysis provides information on the cause(s) of the problem and priority allocation is related to the recognition of the need for action and the acceptance of the responsibility for these actions. Once the danger or the hazard, its causes and its priority are defined, solution generation is a next step. A clear distinction must be made between solution generation and choice of solution. In many cases the solution generation step is cut short or overlooked, due to 'jumping to conclusions'. The implementation of the solution, the monitoring and evaluation of its effects and the planning of contingencies step are the last steps of the cycle. After monitoring and evaluating the effects the cycle is repeated if the danger still remains at an unacceptable level.

\subsection{Design analysis of the workplace}

Design analysis is used in two steps of the problem-solving cycle, problem analysis and solution generation. Design analysis is a descriptive analysis of the structure of a production process (Swuste et al., 1993). It provides systematic answers to the question: What has to be produced and by which combination of methods is that possible? Design analysis makes use of a threefold classification developed in the field of the systematic design of installations. The three levels are interrelated and organized hierarchically. Its basis is the production function, which divides a production process into its core activities which are similar to unit-operations, a classification introduced in 1936 in the chemical industry (Badger and McCare, 1936). The second level is the production principle. This defines the different principles by which the function can be carried out. The production principle includes information on the process, on the energy source in use, and on the operational control method. The operational control method in turn gives an indication of the distance between the worker or operator and the source of hazards. The lowest level is the production form. On this level the actual design of the principles is determined: the detailed design, weight, measurements, speeds, etc.

\subsection{Measurements at workplaces}

In urder to identify factors which influence the vibration exposure of pneumatic drills, vibration measurements were taken at five building sites during the working activities which occur most frequently. The purpose of the measurement programme was to gauge factors as far as possible in an indicative manner. The measurement procedure was according to ISO 5349 standards, using a vibration meter Brüel and Kjær 2513 in combination with a transducer Brüel and Kjær 4392. The intensity was calculated as the weighted effective acceleration in the direction with largest vibration, integrated over a one-minute exposure (ISO, 1986).

A questionnaire was completed, related to the condition of the drill, its state of maintenance, the exposure time, the experience of the worker, the materials to be processed, and to arguments for or against introduction of different solutions to reduce the workload. The information collected and the exposure data, collected under different work conditions were compared. Differences between the means of these measurements were tested by the unpaired Student's $T$-test. In order to investigate interrelationships among important exposure determinants linear regression analysis was also performed. In the empirical models the continuous 
variable (operating pressure), as well as dummy variables (drill make, age of drill, experience of worker and presence of buffer ring) were used. The general equation of the statistical model was:

$$
y=\beta_{0}+\sum \beta_{\mathrm{i}} X_{\mathrm{i}}
$$

The dependent variable $y$ is the weighted effective acceleration, $\beta_{i}$ is the regression coefficient of the independent variable $X_{\mathrm{i}}$; intercept $\beta_{0}$ represents the background exposure level in these models. The regression coefficient represents the contribution of the independent variables per unit to the exposure. The following independent variables were included in the analysis: age of drill (less than one year: 0 , more than one: 1 ), operation pressure (bar), make of hammer (Spitze: 0, Flottman: 1), experience of worker (less than one year: 0, more than one year: 1), presence of buffer ring (no: 0 , yes: 1). The coefficient of a dichotomous dummy variable is the contribution to the exposure of a factor such as age or make of the drill, presence of a buffer ring and experience of the worker, and this presents an estimate of the difference in exposure between workers who differ on these variables.

As well as vibration, other hazards related to the work with pneumatic drills were analyzed. These hazards include noise, working posture, dust and silica exposure and injury risk. The levels of exposure to these hazards were judged qualitatively by the researcher. The levels of exposure were rated in three classes. Class A characterises exposures well inside current accepted standards. No special attention for improvements is needed in the short term. Class $\mathrm{C}$, relates to levels of exposure at the other extreme of the scale where action for improvement is needed in the short term. Class B exposure is positioned between $\mathrm{A}$ and $\mathrm{C}$. The rating in $\mathrm{A}$, $\mathrm{B}$, or $\mathrm{C}$ is therefore a rating of levels of exposure as well as of the period of time in which improvements are regarded to be necessary.

\section{Results}

The exposure to hand-arm vibration varied from 10 to $40 \mathrm{~ms}^{-2}$, with an average of $19.5 \pm 6.5 \mathrm{~ms}^{-2}(n=38)$. Table 1 shows the main results of the measurements, broken down by important exposure determinants. A crude analysis of stratified comparisons identified several important variables which determined vibration intensities. In order to analyze the effects of these factors simultaneously linear regression analysis was performed.

Table 1

Workers' exposure to hand-arm vibration, vibration intensity as weighted effective accelerations

\begin{tabular}{lllcccc}
\hline$n$ & $\begin{array}{l}\text { Drill, } \\
\text { make }\end{array}$ & $\begin{array}{l}\text { Drill, age } \\
\text { (years) }\end{array}$ & $\begin{array}{l}\text { Operating } \\
\text { pressure (bar) }\end{array}$ & $\begin{array}{l}\text { Experience } \\
\text { worker (ycars) }\end{array}$ & $\begin{array}{l}\text { Presence } \\
\text { buffer ring }\end{array}$ & $\begin{array}{l}\text { Vibration intensity } \\
\text { AM } \pm \text { SD (ms }\end{array}$ \\
\hline 3 & Flottmann & $>1$ year & 7 & $>1$ year & + & $11.0 \pm 1.7$ \\
9 & Flottmann & $<$ 1 year & 7 & $>1$ year & + & $15.0 \pm 2.7$ \\
3 & Spitze & $>1$ year & 7 & $>1$ year & + & $20.7 \pm 0.6$ \\
6 & Flottmann & $>1$ year & 8 & $>1$ year & + & $24.0 \pm 2.5$ \\
4 & Flottmann & $>1$ year & 5 & $>1$ year & - & $15.8 \pm 1.7$ \\
7 & Flottmann & $>1$ year & 7 & $>1$ year & - & $26.4 \pm 8.8$ \\
3 & Spitze & $<1$ year & 7 & $>1$ year & - & $17.3 \pm 1.2$ \\
3 & Spitze & $<1$ year & 7 & $<1$ year & - & $22.3 \pm 3.5$
\end{tabular}


First the regression model was tested including the age of the drill and the presence of a buffer ring. Pneumatic drill components such as the piston and cylinder wear out with frequent use. Such wear and tear results in air-leaks between piston and cylinder wall, reducing the impact force of the drill and consequently reducing vibration emission. The buffer ring between chisel and chisel cowl holder ensures that the chisel does not hit the cowl holder directly on return.

The regression model with age of the drill and presence of a buffer ring was significant $(p<0.05)$. The variance of exposure to hand-arm vibration was only partially explained by these two factors $\left(R^{2}=0.18\right)$.

Next the working pressure was introduced into the model. The compressed air which drives the pneumatic drill is varied by a control knob on the compressor. As the pressure is adjusted to a lower level, the impact force of the pneumatic drill is reduced as well as the vibration emission. Introducing working pressure in the model as the third variable enhanced the significance of the model $(p<0.001)$ which explained $46 \%$ of the total exposure variance $\left(R^{2}=0.46\right)$.

The introduction of the make of the drill as well as the experience of the worker did not lead to a significant contribution to the model ( $p=0.9$ and $p=0.7$ respectively).

The model predicts the exposure of a worker according to the following equation: Exposure $=11.1+[4.1$ (old: 0 , new: 1$)]+[5.1(p-5)]+[(-7.4)$ (ring absent: 0 , present: 1)]. Most commonly an old drill was used without a buffer ring and a working pressure of 7 bar, leading to an exposure of $21.3 \mathrm{~ms}^{-2}$. When a drill is optimized from a vibration point of view, equipped with a buffer ring and a working pressure of 5 bar, the predicted exposure will be $3.7 \mathrm{~ms}^{-2}$. But this is only part of the problem and its solution as a full analysis of the current design shows.

\subsection{Extended problem analysis}

The production function is defined as all activities undertaken to change the product to the next production phase. The production function is the difference between the condition before the worker starts to remove the heads of foundation piles and when he is finished. In this case it can be described as 'removing concrete'. Table 2 gives a full description of the analysis of the hazards for the current means of carrying out the production function, both for an average drill and for the 'best' drill, including the rating of the workload for other occupational hazards. The so-called 'best' drill differs from the average drill by operating at a lower working pressure and by the presence of a buffer ring.

The exposure to vibration of the average drill is assessed as a C-category exposure, because the level was well above any standard (ANSI, 1986; NVvA, 1988; ACGIH, 1990; EG, 1994).

The 'best drill' has a vibration exposure of a B-category, because its level is above the action level of $2.5 \mathrm{~ms}^{-2}$.

The exposure to noise, dust and working posture for both type of drills were rated as $\mathrm{C}$ (Andersson, 1990). The noise levels generated made conversation with the worker impossible, thus suggesting an exposure well over $85 \mathrm{~dB}(\mathrm{~A})$.

The hazard from the dust exposure is related to a free-silica emission (Sutter, 1971; Kam, 1993; Lumens and Spee, 1995). The work is predominantly performed in a static position sometimes squatted with severe trunk flexion and rotation and, hence, inflicting large mechanical loads on the back (Punnett et al., 1991). Category C seems to apply. 
Table 2

Design analysis of foundation-pile-head removal

\begin{tabular}{|c|c|c|}
\hline \multirow[t]{2}{*}{ Production function } & \multicolumn{2}{|c|}{ Removing concrete } \\
\hline & Average drill & Best drill \\
\hline \multicolumn{3}{|l|}{ Production principle } \\
\hline process & impact breaking & impact breaking \\
\hline energy & pneumatic & pneumatic \\
\hline operational control method & hand controlled & hand controlled \\
\hline \multicolumn{3}{|l|}{ Execution } \\
\hline \multirow[t]{4}{*}{ construction } & \multicolumn{2}{|c|}{$13-15 \mathrm{~kg}$ pneumatic drill } \\
\hline & pressure: 7 bar & pressure: 5 bar \\
\hline & no buffer ring & buffer ring \\
\hline & old drill & old drill \\
\hline \multicolumn{3}{|l|}{ Occupational hazards } \\
\hline vibration & $\mathrm{C}$ & B \\
\hline noise & $\mathrm{C}$ & $\mathrm{C}$ \\
\hline working posture & $\mathrm{C}$ & $\mathrm{C}$ \\
\hline dust & $\mathrm{C}$ & $\mathrm{C}$ \\
\hline chemicals & - & - \\
\hline climate & $\mathrm{B}$ & $\mathrm{B}$ \\
\hline accidents & B & B \\
\hline environment & A & $\mathrm{A}$ \\
\hline
\end{tabular}

The risk of injury is not very well-known, although several accidents were reported by the interviewees during the workplace visits. Accidents can be caused by the chisel, for example damaging the foot, or falling when the chisel slips or by flying concrete dust and bits. No safety shoes or spectacles were worn: it seems reasonable to assign category B for both types of drills.

\section{Discussion: problem-solving cycle and design analysis}

\subsection{Actual and desired condition, problem recognition and definition}

The description of the actual and desired condition, the problem recognition and definition are the first two steps in the problem-solving cycle. These are summarised in Tables 1 and 2 . The hazards include not only the exposure to vibration, but also to other occupational hazards. The desired condition for all hazards is A or the absence of the factor or at the very least $\mathrm{B}$. According to the ratings given in Table 2 the foundation-pile-head removal using a pneumatic drill calls for major improvements in the short term. This does not apply only to normal pneumatic drills, but even to drills with adjustments to reduce the vibration exposure, like a lower working pressure and the presence of a buffer ring.

\subsection{Problem analysis and priority}

Problem definition overlaps into problem analysis. Once it has been decided who has a problem and what factors are relevant to it, these must be elaborated into a model showing the 
cause-effect relationships which finally lead to the harm which need to be prevented and secondly to factors which facilitate or could block that development.

The first step in the design analysis shows that the production principle used for removing concrete is responsible for high ratings on vibration and other hazards. The hand-controlled operation implies a very short distance from the worker to the hazard source and this combination of a hand-controlled operation using impact breaking, inevitably leads to very high levels of exposure to vibration. If these two principles, the process principle and the operational control method, remain unchanged, a significant improvement in working conditions is not to be expected. This is shown in the rating of the 'best' drill. 'Best' does not refer to best performance in terms of the desired output to break pile heads, just in terms of reduced impact force and thus in reduced vibration emission. Working at a low pressure and using a new drill equipped with a buffer ring will only decrease vibration moderately and but it will still result in the exposure standards being exceeded. Moreover, all other hazards remain unchanged.

The ratings in Table 2 give an indication of the relative weight of individual hazards during hand-held pneumatic drilling activities. The proposed solution, the best drill, is one possible option for reducing the hazards. In the next step, the solution generation, we wish to expand the range of options to be considered. The issue of the absolute priority of this problem, e.g. in relation to other construction site hazards, falls outside the scope of this paper, though the presence of a number of $\mathrm{C}$ ratings indicates that it must have a relatively high absolute priority.

\subsection{Solution generation}

Possible solutions must arise out of the problem model which is constructed. The factors which cause the hazards or the risks or the deviations are the obvious candidates for change. Preventive measures have a tendency to set up a sequence of adjustments and changes which can sometimes result in other problems appearing at a different point in an activity. For instance, the proposed control measures may disrupt the work, have a negative effect on the operators' comfort at work or affect the production output or the employees' control of the work. The generation of solutions must therefore involve a systematic package of measures designed to reduce the hazards in broad terms and to counteract the tendency for the control measure to be eroded. This means that almost, by definition, solutions to risk control problems consist of a mixture of technical and organisational measures.

\subsubsection{Production form}

Some elements for solutions have already been discussed and analyzed in the statistics used, e.g. the machine-related factors such as the age of the drill, its working pressure and the presence of a buffer ring. The results of the hazard ratings (Table 2) suggest the necessity of other routes of prevention, e.g. emission-related instead of exposure-related solutions, in order to arrive at acceptable working conditions.

\subsubsection{Production principle}

A reduction of emission can be achieved by either a variation of the production principle or in a modification of the production function. At this stage of the problem-solving cycle the generation of solutions should be a creative process without too many limitations. A variation in the production principles is realised by changing the process, or the energy source or the 
Table 3

Possible variations in process and energy principles for the function 'foundation pile head removal' and status of technology

\begin{tabular}{|c|c|c|c|}
\hline Process principle & Energy principle & Method of execution & Status of technology \\
\hline \multicolumn{4}{|l|}{ Impact force } \\
\hline impact breaking & pneumatic & remote controlled pneumatic drill & experimental \\
\hline exploding & chemical & explosive holder & experimental \\
\hline pulverising & ultra sonic & acoustic lance & not developed \\
\hline cutting & hydraulic & high pressure water cutter & not developed \\
\hline \multicolumn{4}{|l|}{ Static force } \\
\hline cracking & hydraulic & pile cracker & operational \\
\hline lifting off & hydraulic & muff & not developed \\
\hline \multicolumn{4}{|l|}{ Other processes } \\
\hline burning & thermic & thermal lance & not developed \\
\hline dissolving & chemical & steel collar & experimental \\
\hline
\end{tabular}

distance of the worker to the source of the hazard. In the case of a pneumatic drill the production function 'removing concrete' is achieved by the process principle of impact breaking with a hand-controlled method. Changing the operational control method means, for instance, the introduction of a remote-controlled installation. Other solutions can be generated if process and energy principles are varied. Table 3 gives an overview of possible variations of these principles as well as an indication of the status of the technology involved in them. A few of these solutions are operational, but more of them have the status of 'experimental' or 'not developed'. 'Not developed' means that related principles are already applied in other fields of industry but are not (yet) developed for the specific application under study.

The solutions in Table 3 can be divided into three groups, solutions using impact force to remove the concrete, solutions using static force and a miscellaneous group. In the first group 'solutions using impact force' the concrete removal can be achieved with the use of explosives. Elongated explosive charges are positioned with a explosive holder inside the concrete. This technique is in an experimental stage.

From solutions using static force, head removal with a pile cracker is a new method of operation, using the process principle 'cracking'. The pile cracker consists of a cracking beam which is moved around the head of a foundation pile with the help of a hydraulic crane. This beam contains chisels which are forced hydraulically into the head of the pile. As soon as a layer of concrete, approximately $10 \mathrm{~cm}$, has been 'cracked', the beam is lowered further over the pile and the same process is repeated. This operation is repeated until the foundation pile has been cracked to the desired height. The loosened slabs of concrete are stripped away from the re-enforcement with the help of the crane.

A second solution in this group is the remote-controlled lifting-off of the head of the pile by using a muff during pile driving, protecting the reinforcing rods which have been left bare in casting the pile. This muff can be a piece of concrete of the same properties as the head of the traditional pile, only placed as a removable piece.

From the group 'other processes' the chemical dissolving of concrete is a solution in an experimental phase for concrete removal. Chemicals are spread on the pile and when the concrete is thereby loosened from the reinforcement, it falls into a stainless steel collar fixed around the pile. 


\subsubsection{Production function}

As well as a variation in principles the elimination of a production function also has a dramatic effect on the type and size of occupational hazards. The production function 'removing concrete' can be eliminated by precise pouring of piles fabricated on the spot so that the rods at the top are left free. The choice for on-site pouring of piles rather than pile-driving is now made if big differences in soil structure are to be expected or a large load is to be supported by the pile.

All possible solutions from Table 3, including the elimination of the production function have to be rated for their consequences to occupational hazards. Table 4 shows this rating. Obviously, solutions which are not developed yet or which are experimental cannot be rated by experts with the same reference to experimental data or experience as operational solutions. For this reason a question mark is sometimes used.

The most powerful effect on the type and size of occupational hazards related to 'foundation pile head removal' is the solution of 'on-site precise pouring'. Because the production function is eliminated, its associated hazards are also no longer present. Another operational solution with a profound effect on the size of the hazards is remote-controlled cracking. Here the energy principle as well as the control method are changed. The greater distance of the worker to the sources as well as the much lower impact frequency of cracking compared to impact breaking reduces almost all hazards to acceptable levels.

In general one can say that changing the production principles or production functions has a very direct effect on the size and type of occupational hazards. This is also shown by the other experimental and undeveloped solutions. When adopting for instance a chemical process for head removal, the source of vibration obviously disappears, but a chemical hazard is, of course, introduced which can be serious, due to the aggressiveness required to perform the task. Consequently the hazard rating of chemicals and environment is expected to become a $\mathrm{C}$ rating.

\subsection{Choice of solution}

The choice of solutions is based on a comparison of different solutions to the same problem. Other arguments besides the effects on the hazard and workload will obviously play an important role in the final decision. The costs of the solution, the necessary investments in training of workers, in maintenance schemes or in further adaptations of the work organisation are examples of these arguments. In this study these issues were not systematically explored. In a full analysis these criteria should be listed in addition to the list of hazards of a given solution and should be rated appropriately. By summarising all possible solutions, both those influencing the transmission of vibration and those influencing the source of vibration, an overview can be created of their effects on occupational hazards and financial and organisational consequences. The ultimate choice can be made using an appropriate multi-attribute decision-making tool like, for instance, the Kepner-Tregoe method (Kepner and Tregoe, 1965).

The choice of a solution is closely linked to the acceptance of a solution. In the literature many examples can be found of solutions which were not accepted due to interference with production flow, working procedures, workers' comfort or due to a very poor introduction of the solution (e.g. Antonsson, 1991). These arguments were often heard in the firms in our study using only the hand-operated pneumatic drill. The status of the pneumatic drill, the proven technology with a predictable high quality of work, is rather high. Arguments often 


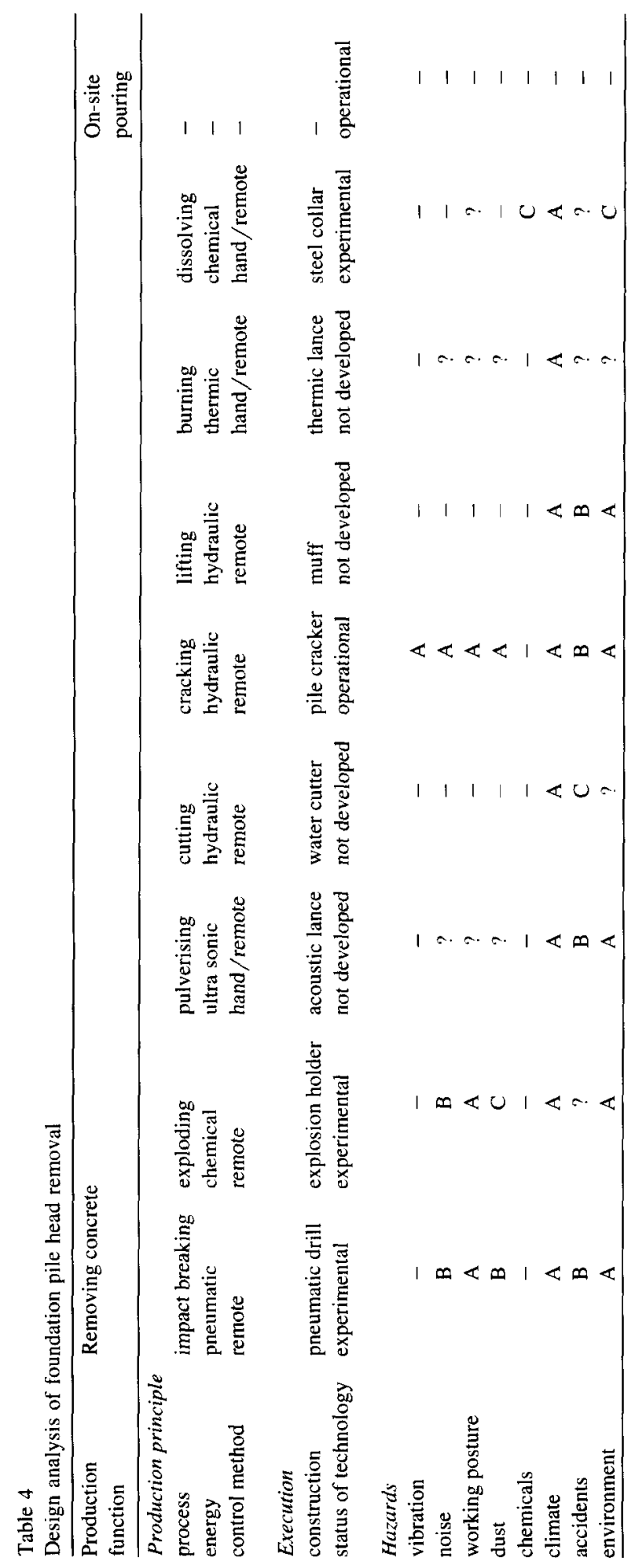


quoted in defence of the pneumatic drill are the low capital investment and the easy accessibility of the drills to the piles compared to a remote-controlled installation.

Adaptations of the pneumatic drill to reduce the level of vibration as mentioned under 'best drill', a lower working pressure and a buffer ring, are not very popular and rarely introduced. A lower working pressure, giving a lower vibration emission also impairs the effectiveness of the drill. The same is true for the buffer ring. This ring is situated underneath the chisel collar. If the drill gets jammed into the concrete so that the chisel is held fast, the ring makes it more difficult to free the drill. For this reason a buffer ring is frequently removed by workers.

Other solutions aimed at reducing hazards during head removal are possible but have a different status of development. Most of these solutions are in an experimental or even a pre-experimental stadium of development. In the long term this is not necessarily a problem, because there will always be trend-setter firms taking the lead in developing solutions. But for the majority of firms only short-term solutions which are already developed will be considered, consequently limiting the choice to pile cracking and on-site precise pouring.

The choice of pile cracking in our sample of companies was not only guided by the firms' concern for occupational hazards, but also by the high productivity of the pile cracker installation. In particular for head removal of a hundred piles or more, a pile cracker can be a very efficient installation. Pile cracking is, however, not yet such a proven technology as pneumatic drilling and demands a greater capital investment. There are still some technical obstacles, for instance, the accessibility of the crane. Compared to pneumatic drilling the pile cracker needs more space between the piles, so the number and the position of the piles needs to be considered when adopting this technique. Another disadvantage of the pile cracker is related to the structure of the pile itself, more specifically the position of the reinforcement rods. If these rods are too close to the surface of the pile the chisels cannot crack the concrete effectively and a pneumatic drill has to be used as well.

For piles fabricated in position the precise pouring technique can eliminate the need for the removal of concrete and it is the best available solution. In the firms using the pouring technique at the time of our study the piles poured on site were still poured with a head and chipped. It was very surprising to see this practice, while no construction requirements prescribe such practice. One can only guess at the arguments. Probably tradition plays an important role in this branch of industry which has, in general, a rather conservative attitude towards safety and health-related issues.

The last two steps of the problem-solving cycle are the implementation of the solution and the feedback loop provided by the process of monitoring and evaluation. These steps fall outside the scope of this paper.

\section{Conclusions}

Hand-operated pneumatic impact breaking is an old-fashioned method for removing the head of foundation piles, leading to an excessive exposure to vibration and high exposures to other occupational hazards. Changing this activity and reducing the workload to acceptable levels requires a systematic approach. The problem-solving cycle provides such a structure. Classification according to the design analysis is a valid method for two stages of the problem-solving cycle, these being the analysis of the exposure in terms of a production process and the generation of different types of solutions and control measures. By varying production principles and the production function a whole range of possible solutions can be 
generated. These will not be considered or evaluated if control measures are only sought in adaptations of the existing drilling technique, e.g. the buffer ring, working pressure, or the age of the drill. By combining the results from design analysis with a qualitative judgement on the different occupational hazards a comparison of the effects of solutions becomes possible. This information can be of value during the choice of the solution.

\section{Acknowledgements}

The vibration measurements were carried out by Harry Hessels and William Verhoeven and the study was supported by a grant from the Dutch Ministry of Social Affairs and Employment.

\section{References}

ACGIH (1990). Supplemental Documentation. Hand-arm (segmental) vibration. American Conference of Governmental Industrial Hygienists, Cincinnati, $\mathrm{OH}$, USA.

Andersson, E. (1990). A systems approach to product design and development. Int. J. Ind. Ergonomics, No. 6, pp. $1-8$.

ANSI (1986). Guide for the measurement and assessment of human exposure to vibration transmitted to the hand. (ANSI S3.34-1986) American National Standards Institute, New York.

Antonsson, A. (1991). Evaluation of failed control measures as a basis for future planning and implementation. In Decision making in the work environment: a focus on chemical health hazards in relation to progressive legislation. Thesis. Department of Work Science, The Royal Institute of Technology, Stockholm, Sweden.

Badger and McCare (1936). Elements of Chemical Engineering, 2nd edn., McGraw-Hill, New York.

EG (1994). Gewijzigd voorstel voor een richtlijn vand de Raad betreffende de minimum voorschriften inzake veiligheid en gezondheid met betrekking tot blootstelling van werknemers aan fysische agentia. Bijzondere richtlijnen in de zin van artikel 16 van Richtlijn 89/391/EEG (94/C 230/03) [Amended proposal for a guideline of the Council for minimum requirements of safety and health related to the exposure of workers to risks of physical agents].

Griffin, M. (1990). Handbook of Human Vibration. Academic Press, Harcourt Brace Jovanovich, Publ,, London.

Hale, A. (1985). The human paradox in technology and safety. Inaugural lecture. Safety Science Group, Delft University of Technology.

Hale, A. and Glendon, A. (1987). Individual Behaviour in the Control of Danger. Elsevier, Amsterdam

Hale, A., de Loor, M., van Drimmelen, D., Huppes, G. (1990). Safety standards, risk analysis and decision making on preventive measures: implications of some recent European legislation and standards. J. Occupational Accidents 13, 213-231.

Hale, A., Heming, B., Carthy, J., Kirwan, B. (1997). Modelling of safety management systems. Safetr. Science 26. $121-140$.

Hessels, H., Verhoeven, W., van Drimmelen, D., Musson, Y., Burdorf, A. (1988). From workplace analysis to solutions: pneumatic chipping leads to unacceptable workload (in dutch), Tijdschrift voor Arbowetenschap 1, 1-5.

ISO (1986). Guidelines for the measurements and the assessment of human exposure to hand-arm vibration. ISO-5349. International Organisation for Standardization, Geneva.

Jacobsson, B., Nordström, B., Lundström, R. (1992). Vibrating hand-arm held machines in the construction industry. Safety Science 15, 367-373.

Kam, J. (1993). Demolition worker hazard. The effect of short term low level combined exposure. J. Enciron. Health 52, 162-163.

Kepner, C. and Tregoe, B. (1965). The Rational Manager. McCraw-Hill, New York.

Lumens, M. and Spee, T. (1995). Silica exposure at construction trades. Presentation at the Annual Conference of the British Occupational Hygiene Society, 27-31 March, Blackpool.

Musson, Y., Burdorf, A., van Drimmelen, D. (1989). Exposure to shock and vibration and symptoms in workers using impact power tools. Ann. Occupational Hyg. 33, 85-96. 
NVvA (1988). Proposal exposure limit hand-arm vibration (in dutch). Nederlandse Vereniging voor Arbeidshygiene (Dutch Occupational Hygiene Society), Den Haag, Netherlands.

Punnett, L., Fine, L., Keyserling, W., Herrin, G., Chaffin, D. (1991). Back disorders and nonneutral trunk postures of automobile assembly workers. Scand. J. Work Environment Health 17, 337-346.

Sutter, E. (1971). Dust measurements during application of gunned concrete in underground construction work. Staub Reinhaltung der Luft 31, 14-16.

Swuste, P., Kromhout, H., Drown, D. (1993). Prevention and control of chemical exposures in the rubber manufacturing industry in the Netherlands. Ann. Occupational Hyg. 37, 117-134.

Taylor, W. (1988). Hand-arm vibration syndrome: a new clinical classification and an updated British standard guide for hand transmitted vibration. Br. J. Ind. Med. 54, 281-282.

van Drimmelen, D., Swuste, P., van der Woude, W., Hoefnagels, W., Musson, Y., Burdorf, A., Hale, A. (1989). An example of solution-directed workplace analysis: Pneumatic chipping of pile heads. Paper presented at the International Symposium of the Research Section of the ISSA 'Vibration at Work', Vienna, Austria, April 19-21.

Wasserman, D. (1989). The control aspects of occupational hand-arm vibration. Appl. Ind. Hyg. 4, F22-26.

Wasserman, D. and Taylor, W. (1991). Lessons from hand-arm vibration syndrome research. Historical perspective in occupational medicine. Am. I. Ind. Med. 19, 539-546. 